\title{
Electrotransformation and natural transformation of Streptococcus pneumoniae: requirement of DNA processing for recombination
}

\author{
Jacques Lefrançois, M. Mustapha Samrakandi and A. Michel Sicard \\ Author for correspondence: Jacques Lefrançois. Tel: +33561335971. Fax: +335613358 86 . \\ e-mail: jacques@ibcg.biotoul.fr
}

Laboratoire de

Microbiologie et de

Génétique Moléculaire du

CNRS and Université Paul

Sabatier, 118 route de

Narbonne, 31062 Toulouse

Cedex, France

\begin{abstract}
Electrotransformation has been used as a tool to introduce genes carried on replicative vectors in hundreds of bacterial species. In this study, the technique was used to try to obtain recombination of markers in the chromosome of the naturally transformable bacterium Streptococcus pneumoniae. Recombination was not observed even using naturally competent cultures. Both chromosomal and cloned DNA, denatured or native, were without effect. These results suggest that it is not sufficient to introduce DNA into the cell to obtain recombinants in this bacterium. The integration of markers into the chromosome in naturally competent cells must require DNA processing during entry. Electrotransformation of replicating plasmids is recA-independent but can be facilitated by a recA-dependent process. This facilitation required the induction of the natural competence machinery, probably involving partial homologous pairing.
\end{abstract}

Keywords: electrotransformation, recombination, plasmid facilitation

\section{INTRODUCTION}

Streptococcus pneumoniae, previously classified as Diplococcus pneumoniae, has preoccupied bacteriologists since the turn of the century when pneumonia was the leading cause of death. A major advance in attempts to protect individuals from infection by using antiserum was the discovery by Heidelberger \& Avery (1922) that the specific antigenic material within the pneumococcus capsule was not a protein but a polysaccharide. As a result of intense investigation of this pathogen, genetic transformation of capsular types was reported by Griffith (1928). This was shown to result from the transfer of DNA by Avery et al. (1944) and the modern field of molecular genetics was born. Over 20 years later, the DNA mismatch repair system was discovered in this organism (Ephrussi-Taylor \& Gray, 1966) and later found in other prokaryotes and eukaryotes. A homologous human system was more recently shown to protect against certain types of colon cancer (Fishel et al., 1993; Leach et al., 1993). Such long-term ramifications of the original discovery of the DNA-induced

Abbreviations: Csp, competence-stimulating peptide; FIGE, field inversion gel electrophoresis; ds, double-stranded; ss, single-stranded. transformation of $S$. pneumoniae could not have been foreseen. The discoveries resulted from continuous investigations of the mechanism of genetic transformation by just a few laboratories (for a review, see Claverys \& Lacks, 1986).

DNA uptake consists of two steps: binding of the DNA to the outer membrane and entry into the cell where the DNA becomes insensitive to DNases (Lacks et al., 1974). Binding causes single-strand breaks in the donor DNA. During entry one of the two strands of donor DNA is degraded to oligonucleotides and the other strand is introduced into the cell in an ss form (Lacks, 1962), probably by the action of endo A nuclease. Specific endlabelling of donor DNA strands has shown that the incoming strand enters in a $3^{\prime}$ to $5^{\prime}$ direction (Méjean \& Claverys, 1988). The entering strand is coated by proteins produced by competent cells (Morrison, 1978). This ssDNA anneals with the complementary strand of the recipient chromosome and becomes physically integrated. During the period when the donor DNA is single-stranded it has no transforming activity (Fox, 1960). This 'eclipse' is due to the inability of ssDNA to efficiently penetrate the bacteria. The half-time for recovery from eclipse at $30^{\circ} \mathrm{C}$ is less than $5 \mathrm{~min}$ for single-site markers (Ghei \& Lacks, 1967). This complex 
processing of DNA requires the activity of several genes. A few of these have been described: endo $A$ encodes an endonuclease (Lacks, 1970; Lacks et al., 1974), comC encodes a peptide that is cleaved to yield a hormone-like 17-aa competence-stimulating peptide (Csp), comD encodes a Csp receptor (Havarstein et al., 1995) and the $r e c A$ operon is required for recombination (Martin et al., 1995).

Is the process of DNA entry into the cell connected with recombination into the chromosome? In other words, is it sufficient to introduce DNA across the cellular envelopes to obtain transformants? To study this process it is possible to use high-intensity electric field pulses to make biomembranes reversibly permeable to DNA and to test for transformability. In a preliminary investigation we were unable to transform chromosomal markers in $S$. pneumoniae by electropermeation (Bonnassie et al., 1989), whereas replicating plasmids were efficiently transferred under the same conditions. There are a number of possible reasons for this failure to obtain chromosomal transformants: inability to detect transformants if they are very rare, absence of induced competence or absence of requirements of the complex process at the entry stages during natural competence to integrate the recipient chromosome. Using electropermeation to introduce DNA into cells, we have shown that the latter hypothesis accounts for our results.

\section{METHODS}

Strains, markers and vectors. The strains of $S$. pneumoniae used in this study are derivatives of R36A (Avery et al., 1944). One of the markers used in the recombination experiments was constructed by insertion of a gene with its own promoter yielding resistance to $4.5 \mu \mathrm{g}$ chloramphenicol $\mathrm{ml}^{-1}$ (Claverys et al., 1995) at a central position in the amiA locus which confers resistance to $2 \times 10^{-5} \mathrm{M}$ amethopterin (Sicard, 1964). This construct, allowing insertion of the chloramphenicol marker by means of surrounding homology provided by the amiA sequence, was cloned in p-Alter1 (Promega) which does not replicate in pneumococci. This vector contains a viral replication origin allowing production of ss phagemid. The other chromosomal marker (str41) confers resistance to $2 \mathrm{mg}$ streptomycin $\mathrm{ml}^{-1}$.

Penetration experiments. The $800 \mathrm{bp}$ ds fragment used in penetration experiments was obtained by PCR amplification of part of the str gene. The ss form of this fragment as well as the 480-base ss str fragment were prepared by the same technique, using unequal amounts of primers to produce a $99 \%$ pure ssDNA. PCR amplification of the whole tet $L$ gene was performed on pLS1 DNA (Lopez et al., 1982). For all penetration experiments, except that of chromosomal DNA, DNA was labelled by PCR, adding $\left[\alpha^{-32} \mathrm{P}\right] \mathrm{dTTP}$ to the dNTP mix, to avoid gaps in the molecules which result in natural uptake interruption (Méjean \& Claverys, 1993).

The labelled chromosomal DNA used in electropenetration and the pLS1 and M13 DNAs used in hybridization experiments were produced with the Megaprime kit (Amersham) which incorporates labelled dNTPs by elongating randomly hybridized degenerate primers. Electropenetration was carried out as described below for electroporation. The cells were washed twice before measuring retained radioactivity. The operation was repeated without electric shock and the results compared. Natural penetration experiments were conducted in the same way, replacing electric treatment by natural penetration.

Field inversion gel electrophoresis (FIGE). FIGE has been described in detail by Kauc et al. (1989) and Gasc et al. (1991). Southern blot hybridizations (Southern, 1975) were performed as described by Sambrook et al. (1989) at $55^{\circ} \mathrm{C}$.

Preparation of competent cells and transformation. Natural competence was obtained from exponentially growing cultures in CAT medium (Morrison et al., 1983) supplemented with $0.2 \%$ bovine serum albumin and $10^{-3} \mathrm{M} \mathrm{CaCl}_{2}$ (final concentrations). The cells were centrifuged and resuspended in the same medium supplemented with $3 \times 10^{-3} \mathrm{M} \mathrm{NaOH}$

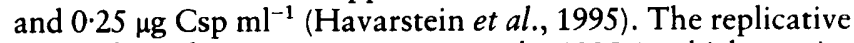
plasmid used was pSP2 (Prats et al., 1985a) which carries resistance markers for erythromycin and tetracycline. Transformants were selected after incubation for $2 \mathrm{~h}$ at $37^{\circ} \mathrm{C}$ on selective plates $\left(1.5 \mu \mathrm{g}\right.$ tetracycline $\left.\mathrm{ml}^{-1}\right)$ to test for plasmid replication in the recipients. When used in facilitation experiments, pSP2 harboured either an $S$. pneumoniae insert of about $1.5 \mathrm{~kb}$ or a $1.4 \mathrm{~kb}$ Escherichia coli insert (Prats et al., 1985b).

For electrotransformation experiments, cells were grown at $37^{\circ} \mathrm{C}$ in CAT complete medium (Morrison et al., 1983) supplemented with $2 \%$ bovine serum albumin (final concentration) and harvested in the early exponential growth phase $\left(\mathrm{OD}_{600} 0 \cdot 1-0 \cdot 2\right)$. They were washed twice and concentrated tenfold in electroporation medium $(0.5 \mathrm{M}$ sucrose, $7 \mathrm{mM}$ potassium phosphate, $\left.\mathrm{pH} 7 \cdot 5,1 \mathrm{mM} \mathrm{MgCl}_{2}\right)$. A volume of $0.8 \mathrm{ml}$ cell suspension was poured into a Bio-Rad cuvette. Plasmid DNA was added at a concentration of $1 \mu \mathrm{g} \mathrm{ml}^{-1}$ and chromosomal DNA at $20 \mu \mathrm{g} \mathrm{ml}^{-1}$. The mixture was kept at $0{ }^{\circ} \mathrm{C}$ for $10 \mathrm{~min}$. A single impulse of current was given with the Bio-Rad apparatus set at maximum $\left(6 \cdot 25 \mathrm{kV} \mathrm{cm}^{-1}, 25 \mu \mathrm{F}\right)$.

\section{RESULTS AND DISCUSSION}

\section{Test for electrotransformation of chromosomal markers}

Electrotransformation of wild-type strain 800 was performed as described in Methods. When DNA from plasmid pSP2 was used, transformants selected for their resistance to erythromycin were obtained at the usual frequency (Table 1). With chromosomal DNA carrying the str41 marker, transformants could not be selected even at the highest concentration of DNA $\left(20 \mu \mathrm{g} \mathrm{ml}^{-1}\right)$. Spontaneous mutants resistant to streptomycin $\left(200 \mu \mathrm{g} \mathrm{ml}^{-1}\right)$ were also undetectable. Even upon increasing the number of bacteria plated to the upper limit allowing selection, transformants were undetectable. We could estimate that the frequency of marker rescue was below $10^{-9}$ per viable cell. Therefore, penetration of chromosomal DNA in S. pneumoniae by high-intensity electric fields was not sufficient to obtain transformants. We have previously reported that under these conditions dsDNA penetrates into these bacteria without a singlestrand step in contrast to natural transformation (Lefrançois \& Sicard, 1997). A possibility is that ssDNA is required to recombine with the chromosome. As denatured plasmid DNA yields electrotransformants, although at a reduced frequency (Lefrançois \& Sicard, 1997), we tested boiled chromosomal DNA. Electro- 


\section{Table 1. Electrotransformation experiments using chromosomal or plasmid DNA}

Strain R800 (Lefevre et al., 1979) was used in all experiments. Induction of natural competence was obtained by addition of Csp.

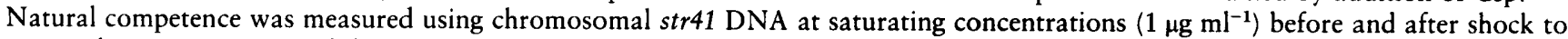
ensure that it was conserved during the operation. To prevent natural transformation, pancreatic DNase $\left(50 \mu \mathrm{g} \mathrm{ml^{-1 } )} \mathrm{was}^{\mathrm{added}}\right.$ immediately $(<2 s)$ after the electric pulse. A control experiment without electric shock was also performed under the same conditions and did not yield any transformants. Plasmid pSP2 is a replicative plasmid in S. pneumoniae. Plasmid pAmC is an E. coli plasmid that does not replicate in this bacterium; it contains the chloramphenicol resistance gene inserted in the amiA locus. The synthesized oligonucleotide $60 \mathrm{str}$ carries the $\mathrm{str} 41$ mutation, as does $480 \mathrm{str}$ obtained by PCR amplification. DNA was used at a concentration of $1 \mu \mathrm{g} \mathrm{ml}^{-1}$ except in expts $3\left(4 \mu \mathrm{g} \mathrm{ml}^{-1}\right)$ and $4\left(12 \mu \mathrm{g} \mathrm{m}^{-1}\right)$. When survival was in the $10 \%$ range, electroporation was performed in $0.5 \mathrm{M}$ sucrose instead of the buffer described in Methods.

\begin{tabular}{|c|c|c|c|c|c|c|c|c|c|c|c|}
\hline \multirow[t]{2}{*}{ Expt } & \multicolumn{2}{|c|}{$\begin{array}{l}\text { Processing of the } \\
\text { recipient strain }\end{array}$} & \multirow{2}{*}{$\begin{array}{c}\text { Natural } \\
\text { competence }(\%)\end{array}$} & \multirow{2}{*}{$\begin{array}{c}\text { Survival after } \\
\text { pulse }(\%)\end{array}$} & \multicolumn{7}{|c|}{ Transformation frequency } \\
\hline & $\begin{array}{c}\text { Natural } \\
\text { competence }\end{array}$ & $\begin{array}{c}\text { Electric } \\
\text { pulse }\end{array}$ & & & $\begin{array}{c}\text { pSP2 } \\
\text { (circular) }\end{array}$ & $\begin{array}{c}\text { Native } \\
\text { chromosomal str }\end{array}$ & $\begin{array}{c}\text { Denatured } \\
\text { chromosomal str }\end{array}$ & $\begin{array}{c}\text { pAmC } \\
\text { (ds circular) }\end{array}$ & $\begin{array}{c}\text { pAmC } \\
\text { (ss circular) }\end{array}$ & $\begin{array}{c}60 \text { str } \\
\text { (ss linear) }\end{array}$ & $\begin{array}{c}480 \text { str } \\
\text { (ss linear) }\end{array}$ \\
\hline la & - & + & & $10 \cdot 9$ & $2.3 \times 10^{-5}$ & & & & & & \\
\hline Ib & - & + & & 10.6 & & $<10^{-8}$ & & & & & \\
\hline 2 & - & + & & 53.8 & & & $<10^{-9}$ & & & & \\
\hline 3 & - & + & & $73 \cdot 0$ & & & & $<10^{-8}$ & & & \\
\hline 4 & - & + & & $43 \cdot 0$ & & & & & $<10^{-8}$ & & \\
\hline $5 a$ & + & + & $1 \cdot 2$ & 7.0 & $3.1 \times 10^{-4}$ & & & & & & \\
\hline $5 b$ & + & + & $1 \cdot 2$ & $9 \cdot 4$ & & $<10^{-8}$ & & & & & \\
\hline 6 & + & + & $3 \cdot 6$ & $67 \cdot 2$ & & & $<10^{-8}$ & & & & \\
\hline 7 & + & + & $2 \cdot 9$ & $90 \cdot 0$ & & & & $<10^{-8}$ & & & \\
\hline 8 & + & + & $3 \cdot 5$ & $49 \cdot 7$ & & & & & $<10^{-8}$ & & \\
\hline 9 & + & + & 3.55 & $71 \cdot 7$ & & & & & & $1.4 \times 10^{-7}$ & \\
\hline 10 & + & + & 3.5 & 56.5 & & & & & & & $9.6 \times 10^{-7}$ \\
\hline 11 & - & + & & 53.9 & & & & & & $<10^{-8}$ & \\
\hline 12 & - & + & & 55.6 & & & & & & & $<10^{-9}$ \\
\hline
\end{tabular}

Table 2. Penetration of ds- and ssDNA during electroporation

Labelled DNA was produced as indicated in Methods. Each assay was performed with equivalent numbers of cells $\left(0 \cdot 4 \times 10^{8}\right)$. The strain used was R800.

\begin{tabular}{|lccc|}
\hline DNA $\left(\mathrm{ng} \mathrm{ml}^{-1}\right.$ ) & Electropermeabilization & $\begin{array}{c}\text { Radioactivity } \\
\text { retained after } \\
\text { washing (c.p.m.) }\end{array}$ & $\begin{array}{c}\text { Total radioactivity in } \\
\text { sample labelled DNA used } \\
\text { in each assay (c.p.m.) }\end{array}$ \\
\hline Chromosomal (210) & + & 13160 & $8 \cdot 16 \times 10^{5}$ \\
Chromosomal (210) & - & 3265 & $8 \cdot 16 \times 10^{5}$ \\
pLS1 (21) & + & 12944 & $15 \cdot 5 \times 10^{5}$ \\
pLS1 (21) & - & 6543 & $15 \cdot 5 \times 10^{5}$ \\
800 bp ds fragment 1 (560) & + & 18784 & $4 \cdot 09 \times 10^{5}$ \\
800 bp ds fragment 1 (560) & - & 3117 & $4 \cdot 09 \times 10^{5}$ \\
800 bp ds fragment 2 (5600) & + & 52142 & $4 \cdot 06 \times 10^{6}$ \\
800 bp ds fragment 2 (5600) & - & 37341 & $4 \cdot 06 \times 10^{6}$ \\
800 bases ss fragment (230) & + & 47911 & $3.65 \times 10^{6}$ \\
800 bases ss fragment (230) & - & 30414 & $3 \cdot 65 \times 10^{6}$ \\
\hline
\end{tabular}

transformants were not observed (Table 1, expt 2). To increase the sensitivity of detection of rare transformants we cloned a fragment of DNA carrying a marker conferring resistance to chloramphenicol flanked by $S$. pneumoniae amiA sequences in the plasmid pAmC that replicates in $E$. coli but not in $S$. pneumoniae. This plasmid can be obtained either as ds- (replicative form) or ssDNA (as described in the Methods) and in naturally competent $S$. pneumoniae cultures it yields chloramphenicol transformants by insertion in the chromosome at the amiA locus. Electrotransformants could not be observed using either ds or ss circular forms of this DNA (expts 3 and 4). Similar assays for chromosomal markers conferring either resistance to cefotaxime [carried on a $2 \mathrm{~kb}$ PCR fragment amplified from the gene encoding penicillin-binding protein $2 \mathrm{x}$ (Laible et al., 1989)] or sensitivity to amethopterin [carried on phage M13 and screened for the ability to grow on a synthetic medium containing an excess of isoleucine (Sicard, 1964)] were also unsuccessful. 
Therefore, penetration of ds- or ssDNA by electropermeabilization is not sufficient to obtain chromosomal recombinants. Other steps that are induced during natural competence might be required to insert the incoming DNA into the chromosome. The many proteins that are overexpressed or newly synthesized during natural competence (Morrison \& Baker, 1979) might catalyse such steps.

\section{Electrotransformation of naturally competent cultures}

Exponential cultures were grown and treated with Csp as described in Methods. A sample was mixed with DNA carrying the str41 marker to measure natural competence. The frequency of natural transformation was greater than $3 \%$ (Table 1, expts 5-10). Highintensity electric field treatment was applied in the following experiments. Pancreatic DNase was added at a concentration of $5 \mu \mathrm{g} \mathrm{ml}^{-1}$ to the cuvette immediately after the electric shock $(<2 \mathrm{~s})$. DNase was also added to agar medium to avoid the effects of natural competence on plates, an event that we have observed when Csp is used. As a control, an aliquot of the same culture was mixed with the same DNA in the cuvette without electric shock and DNase was added within $<2 \mathrm{~s}$. Transformants were not detectable. This shows that under these conditions the cells were competent but during this very short period of time the marker carried by the DNA molecule did not enter the bacteria. This was expected since natural penetration of DNA is a relatively slow process (Kent \& Hotchkiss, 1964). The first transformants can only be detected when DNase is added $20 \mathrm{~s}$ after the DNA is mixed with the cells and penetration of $50 \%$ of the molecules requires $7 \mathrm{~min}$ (A. M. Sicard, unpublished results). When aliquots of the same culture were electropermeabilized in the presence of the chromosomal str41 marker and DNase added immediately, transformants were not observed (Table 1, expt $5 \mathrm{~b}$ ). ssDNA was also ineffective (expt 6). Both forms of the plasmids were also inefficient when natural competence was induced (expts 7 and 8).

We tried to increase the probability of obtaining electrotransformants by using medium-length oligonucleotides carrying a resistance marker. If such a short region of homology could produce transformants compared to a marker carried by a several kilobase plasmid, the sensitivity of the test could be significantly improved because of the increased molarity with respect to the mass. We synthesized a 60 -base oligonucleotide carrying the str41 marker $(60 s t r)$. A PCR-amplified $480 \mathrm{nt}$ ssDNA $(99 \%)$ carrying the same mutation in a central position was also synthesized (480 str). It can be seen from Table 1 that few transformants were obtained (expts 9 and 10). Their identity was verified by further cultivation and resistance measurements. In the absence of competence, electrotransformants were not observed (expts 11 and 12). Therefore, it is very difficult or impossible to obtain electrotransformants with several kinds of DNA when chromosomal recombination is required, even when natural competence is induced. Rare electrotransformants were obtained when an oligonucleotide carrying the streptomycin resistance marker was used after induction of natural competence.

One might wonder if chromosomal DNA penetrates during electroporation. To answer this question, we labelled several DNA preparations and measured the radioactivity of washed cells after electric pulse. The data in Table 2 show that chromosomal DNA does penetrate, as well as plasmid DNA. Therefore, the absence of transformants was not due to a defect of penetration. Short $(800 \mathrm{bp}) \mathrm{ds}$ and ss fragments do penetrate, although less efficiently than chromosomal or plasmid DNA.

A hypothesis to account for the absence of transformants could be that the electric pulse inactivated the recombination machinery of the bacteria. It is possible to test for this activity by investigating plasmid facilitation that requires recombination (Lopez et al., 1982).

\section{Facilitation of plasmid transfer by electrotransformation}

In natural transformation, plasmid donor DNA is converted on entry to a linear single strand of one genome length or less due to DNA degradation. Establishment of the plasmid requires the interaction of two overlapping fragments to reconstitute the replicon. When the plasmid carries a segment of DNA homologous to the host chromosome, the frequency of plasmid transfer is drastically increased (Table 3). This observation, named facilitation, depends on synapsis, homology and recombination of the entering ss plasmid molecule with the host chromosome (Lopez et al., 1982). In the absence of homology with the chromosome, establishment of plasmids also requires pairing between two partial plasmid genomes. As there is no evidence for a single-strand step or DNA degradation during electropenetration, facilitation was not anticipated. Moreover, the interaction of two plasmid molecules to obtain complete plasmid replicons was supported by the observation that in naturally competent cells the frequency of plasmid transformation of monomeric plasmid DNA without homology with the chromosome depends quadratically on the DNA concentration (Saunders \& Guild, 1981). In contrast, dependence of plasmid electrotransformation on DNA concentration is linear, arguing against interaction between plasmid genomes (Bonnassie et al., 1989). Nevertheless, we looked for facilitation during electrotransformation.

We submitted to electric shock naturally competent or non-competent cultures mixed with pSP2 plasmid DNA carrying an erythromycin resistance gene and transformants were selected. When pSP2 containing a $1.5 \mathrm{~kb}$ fragment of chromosomal DNA was used in a first experiment, induction of natural competence increased the transformation frequency 56-fold compared to electrotransformants. With pSP2 carrying a heterologous fragment from $E$. coli of the same length there 


\section{Table 3. Plasmid facilitation during electrotransformation}

Cultures of both strains were divided, one part was induced to natural competence by addition of

Csp and then both were submitted to the electric pulse. To prevent natural transformation, pancreatic DNase $\left(50 \mu \mathrm{g} \mathrm{ml}^{-1}\right)$ was added immediately $(<2 \mathrm{~s})$ after the electric pulse. A control experiment without electric shock was also performed under the same conditions and did not yield any transformants. In all cases when naturally competent cells were electroporated, natural competence was measured for the str41 marker before and after shock to ensure that it was conserved during the experiment. Plasmid pSP2 homol contains approximately $1.5 \mathrm{~kb}$ chromosomal DNA; pSP2 hetero contains $1.4 \mathrm{~kb}$ E. coli DNA. Both plasmids were used at a concentration of $1 \mu \mathrm{g} \mathrm{ml}^{-1}$. The mean survival after electrotransformation was $73 \%$. In four independent experiments, the mean efficiency observed for $\mathrm{PSP} 2 \mathrm{homol}$ in a $\mathrm{rec} \mathrm{A}^{+}$naturally competent background was $47 \cdot 3$ times the efficiency observed in the same non-competent strain $(\mathrm{SD}=7 \cdot 3)$. The efficiency observed for pSP2 hetero with competent cultures was 7 times that observed for noncompetent cultures $(S D=2 \cdot 9)$. The mean competence rate was $3.4 \%(S D=1 \cdot 8)$.

\begin{tabular}{|cccccc|}
\hline Strain & $\begin{array}{c}\text { Natural } \\
\text { competence }\end{array}$ & DNA & DNase & $\begin{array}{c}\text { Electric } \\
\text { pulse }\end{array}$ & $\begin{array}{c}\text { Transformation } \\
\text { frequency }\end{array}$ \\
\hline${\text { rec } A^{+}}^{+}$ & + & str41 & + & - & $<2 \times 10^{-7}$ \\
& + & str41 & - & - & $3.8 \%$ \\
& - & pSP2 homol & + & + & $0.96 \times 10^{-6}$ \\
& - & pSP2 hetero & + & + & $0.2 \times 10^{-5}$ \\
& + & pSP2 homol & + & + & $5.43 \times 10^{-5}$ \\
$r e c A^{-}$ & + & pSP2 hetero & + & + & $2.32 \times 10^{-5}$ \\
& - & pSP2 homol & + & + & $0.66 \times 10^{-5}$ \\
& - & pSP2 hetero & + & + & $0.40 \times 10^{-5}$ \\
& + & pSP2 homol & + & + & $0.36 \times 10^{-5}$ \\
& + & pSP2 hetero & + & + & $0.44 \times 10^{-5}$ \\
\hline
\end{tabular}

was a 12 -fold increase (Table 3 ). In three other experiments under the same conditions these factors were 53.2-, 42- and 38-fold for competence induction using plasmids with a homologous insert and 5.6-4.4- and 6fold when the insert was heterologous, respectively. Therefore, the induction of natural competence strongly increases establishment of replicative plasmids.

Among the many proteins overexpressed during competence (Martin et al., 1995), recA is a good candidate to play a role in this phenomenon. We have used a $\operatorname{rec} A^{-}$ strain that is completely blocked in recombination due to an insertion in the gene and consequently this strain is not naturally transformable. In Table 3 it is clear that in this $\operatorname{rec} A^{-}$strain, the efficiency of electrotransformation was constant whatever plasmid was used. As there was no natural transformation when the $r e c A^{-}$strain was used as receptor, even with the addition of Csp, it was necessary to ensure that DNA was taken up under these conditions. Labelled DNA was mixed with Csptreated or untreated $\operatorname{rec} A^{+}$or $r e c A^{-}$strains under identical conditions and radioactivity was measured after washing the bacterial suspension. All tests were made with equivalent amounts of both DNA and cells and the total radioactivity used in each assay was $8 \cdot 26 \times 10^{4}$ c.p.m. The background radioactivity retained by non-competent cell surfaces was 304 c.p.m. for the $r e c A^{+}$strain and 407 c.p.m. for the $r e c A^{-}$strain. The radioactivity measured in each induced strain after transformation was 5716 c.p.m. for the $r e c A^{+}$strain and 4662 c.p.m. for the $r e c A^{-}$strain: they had incorporated similar amounts of DNA. This shows that the $\operatorname{rec} \mathrm{A}^{-}$ strain was induced to natural uptake at the same level as the $r e c A^{+}$strain. The natural competence rate of the $\operatorname{rec} \mathrm{A}^{+}$culture, as measured by natural transformation with chromosomal DNA containing a marker conferring streptomycin resistance, was $6 \cdot 2 \%$.

Surprisingly, the efficiency of $\mathrm{recA}^{+}$electrotransformation was also increased by Csp treatment when the plasmid carrying a heterologous fragment of DNA was used. This increase was abolished in the $r e c A^{-}$background as shown in Table 3 . The requirement of recA suggests that even for this plasmid, a recombination process facilitates its establishment.

A hypothesis could be that, similar to natural transformation, electrotransformation in a $\mathrm{recA}^{+}$background may involve pairing between two plasmid genomes that have been more or less degraded. This could explain the increased number of transformed cells with regard to experiments driven with $r e c A^{-}$strains. If this was true, the transformation frequency would depend quadratically on DNA concentration because the probability of giving rise to a new replicon depends on the presence of at least two independently penetrated molecules inside the cell. Thus, facilitation of plasmid electroporation was measured at different DNA concentrations. Naturally competent cultures were mixed with DNA, electroporated and DNase was added immediately to prevent natural transformation as already described. In Fig. 1 we can see that the frequency of 


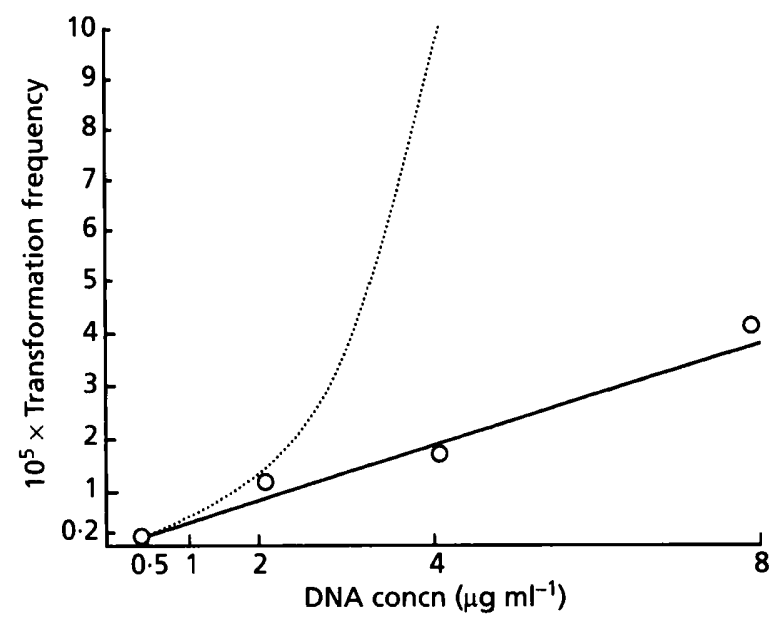

Fig. 1. Linear dependence of facilitation on DNA concentration in electrotransformation of competent cells with pLS1. Solid line, experimental curve showing linear dependence; dotted line, theoretical curve, assuming that the interaction between two plasmids determines the enhancement of pLS1 transfer in competent cells. The equation of this curve is $F_{n}=$ [ $\left.n,\left(0.83 \times F_{0.5}\right)\right]^{2}+n\left(0.17 \times F_{0.5}\right)$, where $n$ is the ratio of the tested DNA concentration to the concentration tested initially $\left(0.5 \mu \mathrm{g} \mathrm{ml}^{-1}\right), F_{\mathrm{n}}$ is the theoretical frequency corresponding to a concentration $n$-fold greater than $0.5 \mu \mathrm{g} \mathrm{ml}^{-1}$ and $F_{0.5}$ is the frequency observed at $0.5 \mu \mathrm{g}$ DNA $\mathrm{ml}^{-1}$. The $F_{0.5}$ multiplicative factor in the equation is calculated assuming that, as observed, the competence-specific enhancement produces a sixfold greater transformation frequency for $0.5 \mu \mathrm{g} \mathrm{pLS1} \mathrm{DNA} \mathrm{ml}{ }^{-1}$, the frequency ratio of competence-specific enhancement is 0.83 and the frequency ratio characteristic of non-competent cells is 0.17 . The strain used was R800. Natural competence $(1.5 \%)$ was obtained by addition of Csp. The apparatus settings were $25 \mu \mathrm{F}$ and $2.5 \mathrm{kV}$ using $0.4 \mathrm{~cm}$ wide cuvettes, the ionic buffer described in Methods and a $200 \Omega$ shunter.

electrotransformation is proportional to DNA concentration. The theoretical curve for a quadratic function, taking into account that in this experiment $83 \%$ of the transformants result from an enhancement of the transfer in a competent background, clearly deviates from the experimental results. This suggests that inside the cell there is no important interaction between plasmid molecules. Therefore, it is likely that this recAdependent facilitation proceeds through a partial pairing between plasmid DNA and the S. pneumoniae chromosome.

\section{Search for homology between plasmids and the S. pneumoniae chromosome}

To test the hypothesis of partial homology between the vector and the chromosome, pLS1 and pSP2 harbouring either the homologous or the heterologous insert were labelled as described in Methods and used as probes for autoradiography of chromosomal fragments separated by conventional electrophoresis or PFGE. Several hybridization bands were obtained for EcoRI-digested $S$. pneumoniae chromosomal fragments with all three

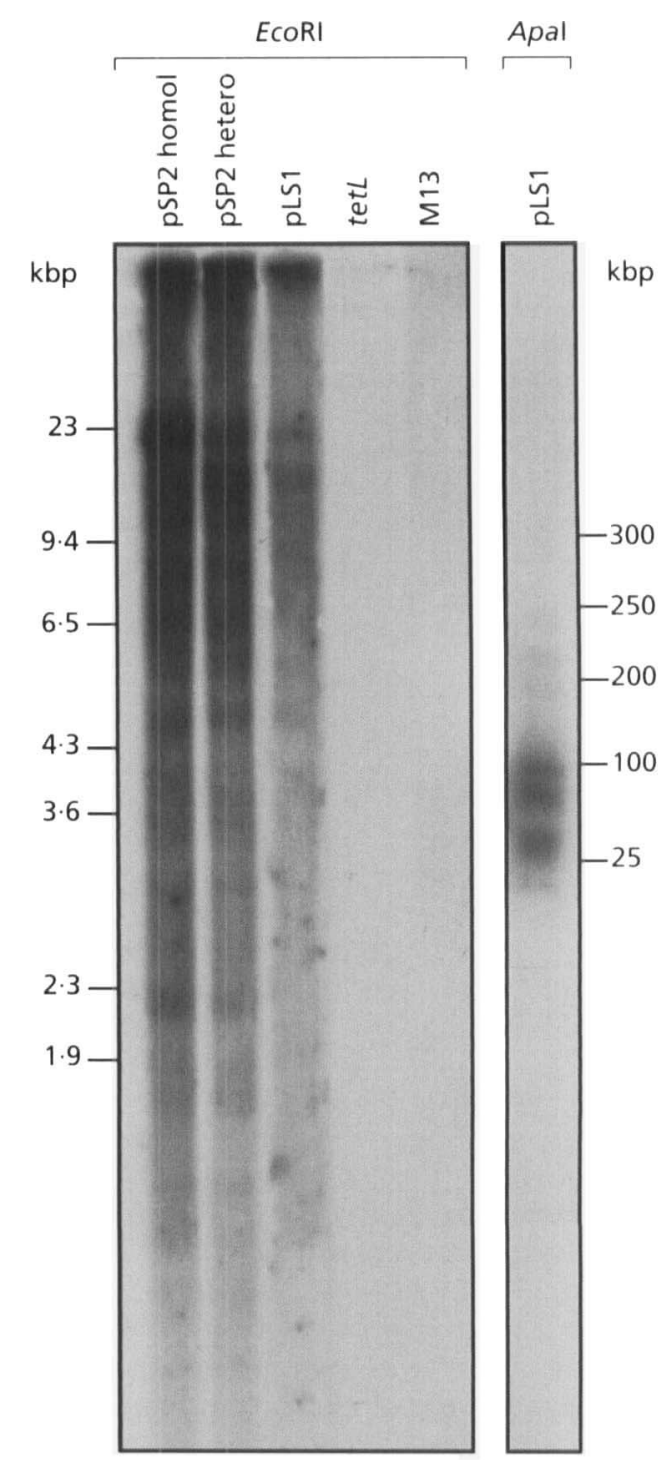

Fig. 2. Hybridization assay between fragments of the $S$. pneumoniae chromosome and several probes. Southern blot hybridizations were performed at $55^{\circ} \mathrm{C}$; pLS1 carries tetL; pSP2 homol and hetero are derived from pLS1 and contain $1.5 \mathrm{~kb}$ $S$. pneumoniae or $1.4 \mathrm{~kb} E$. coli DNA, respectively, inserted between two erythromycin resistance genes. M13 was used as a control; tetL is a PCR product. All the probes were tested on EcoRI digests of the $S$. pneumoniae chromosome, pLS1 was also hybridized to Apal fragments separated by FIGE.

probes as shown in Fig. 2. Under the same conditions an M13 probe did not show any hybridization bands. Three major bands of medium size $(25-100 \mathrm{~kb})$ separated by FIGE after ApaI digestion also hybridized with the pLS1 probe. Therefore, the plasmid genome contains sequences homologous to several regions of the chromosome. When plasmid pSP2 carrying a $1.5 \mathrm{~kb} S$. pneumoniae insert was tested for hybridization, a very strong band corresponding to this insert was observed as expected. It is noteworthy that the pattern of hybridization is the same for all three plasmid probes. Plasmid 
Psp2 is derived from pLS1 with the addition of two erythromycin resistance genes and either a $1.4 \mathrm{~kb} E c o$ RI insert or a $1.5 \mathrm{~kb}$ S. pneumoniae insert. Therefore, these DNA sequences, which are not shared by all the probes, cannot be responsible for the identical profile. Hence, they are not involved in the homologous regions. Moreover, a probe from the tetracycline resistance gene (tet $L$ ) harboured by all three vectors did not hybridize with the chromosome under the same conditions, suggesting that the remainder of the pLS1 vector, which is also a common part of all the probes, could be responsible for the profile identity and contains sequences homologous or partially homologous to the chromosome.

\section{Conclusions}

Attempts to obtain electrotransformants for chromosomal markers was unsuccessful even when the natural competence machinery was induced and/or when denatured DNA was used to mimic natural uptake. This suggests that the process of entry during natural competence is required to obtain chromosomal recombinants. In natural transformation all ssDNA is associated with proteins in the eclipse complex which protects the entering DNA from nuclease degradation (Morrison, 1978). In electropermeation, this step might be impossible due to the very rapid penetration. Indeed, this process might be even more complex than the steps already described. It appears that one, several or may be all these events are necessary to yield chromosomal recombinants. During natural competence, not only does the DNA penetrate into the cell, but it is also processed to prepare for $r e c A$-dependent homologous recombination in the chromosome. This event is not required for plasmid replication. The other alternative of inactivation of the recombination apparatus by the electric pulse was excluded by the evidence of recombination-dependent plasmid facilitation during electrotransformation.

Failure to obtain chromosomal electrotransformants is generally observed. In Haemophilus influenzae, another naturally competent bacterium, this failure has also been reported (Mitchell et al., 1991) and, as we have found, natural competence induction was no more successful.

It is noteworthy that in $r e c A^{-}$strains plasmid establishment is efficiently obtained by electrotransformation, in contrast with natural competence where recA-dependent recombination occurs between two ssDNA molecules containing part of the plasmid genome (Martin et al., 1995). This is in agreement with the demonstration that dsDNA penetrates $S$. pneumoniae during electroporation (Lefrançois \& Sicard, 1997) and suggests that this DNA contains an intact genome ready for replication.

We have observed that induction of natural competence markedly increases the establishment of a plasmid containing a fragment homologous to the chromosome. This facilitation, first described by Lacks and co-workers in a slightly different system (Lopez et al., 1982), is recAdependent, confirming the requirement of recombination to explain the original facilitation experiments. When the vector used in our electrotransformation studies carries a heterologous fragment of the same size as the $S$. pneumoniae fragment, there is still an increased electrotransformation, although at a reduced level. This phenomenon is also recA-dependent. It cannot be explained by an interaction between two degraded plasmids, since the frequency of electrotransformation is proportional to DNA concentration. The more likely interpretation is that facilitation results from partial pairing of the plasmid DNA with the chromosome through some homologous sequences. This could account for the origin of plasmid resistance genes transferred from the bacterial chromosome either as wild-type or resistant alleles. Further investigations are in progress to test this hypothesis.

Facilitation of plasmid establishment when the natural competence machinery is turned on in a $\mathrm{rec}^{+}$background might suggest that plasmids used in electrotransformation contain substantial lesions that are repaired by $\operatorname{rec} A$-dependent recombination to allow successful replication. These lesions could be singlestrand interruptions, gaps or partial denaturation occurring during plasmid preparation or during the electric-pulse-dependent penetration of the DNA. However, the electric pulse by itself has no effect on DNA in solution (data not shown). It is possible that inside the cell, plasmid DNA not coated by the proteins induced by natural competence could be the target of DNases. Pairing in a recA-dependent way would protect these molecules.

Electrotransformation has been generally used to introduce plasmid DNA in hundreds of bacterial species for developing molecular genetic and biotechnological techniques. In this study we have used this method to obtain plasmid installation in recombination-deficient $\left(r e c A^{-}\right)$strains and to investigate the mechanism of natural competence. Therefore, electrotransformation is not only a tool for biotechnological studies but is also a tool for fundamental research.

\section{ACKNOWLEDGEMENTS}

We thank D. Morrison for his gift of the competence stimulating factor, B. Martin for the $r e c A^{-}$strain and plasmids pR327 and pSP2 carrying the heterologous insert, S. Lacks for his suggestion of a possible interaction between two damaged plasmids in electrofacilitation of pLS1 and A. Carpousis for his help in preparing the manuscript. This work was partly supported by the Université Paul Sabatier.

\section{REFERENCES}

Avery, O. T., MacLeod, C. M. \& McCarty, M. (1944). Studies on the chemical nature of the substance inducing transformation of pneumococcal types. I. Induction of transformation by a desoxyribonucleic acid fraction isolated from pneumococcus type III. J Exp Med 79, 137-158.

Bonnassie, S., Gasc, A. M. \& Sicard, A. M. (1989). Transformation by electroporation of two Gram-positive bacteria: Streptococcus 
pneumoniae and Brevibacterium lactofermentum. In Genetic Transformation and Expression, pp. 71-75. Andover: Intercept.

Claverys, J. P. \& Lacks, S. A. (1986). Heteroduplex deoxyribonucleic acid base mismatch repair in bacteria. Microbiol Rev 50, 133-165.

Claverys, J. P., Dintilhac, A., Pestova, E. V., Martin, B. \& Morrison, D. A. (1995). Construction and evaluation of new drug-resistance cassettes for gene disruption mutagenesis in Streptococcus pneumoniae, using an ami test platform. Gene 164, 123-128.

Ephrussi-Taylor, H. \& Gray, T. C. (1966). Genetic studies of recombining DNA in pneumococcal transformation. J Gen Physiol 49, 211-231.

Fishel, R., Lescoe, M. K., Rao, M. R. S., Copeland, N. G., Jenkins, N. A., Garber, J., Kane, M. \& Kolodner, R. (1993). The human mutator gene homolog $\mathrm{MSH} 2$ and its association with hereditary nonpolyposis colon cancer. Cell 75, 1027-1038.

Fox, M. (1960). Fate of transforming deoxyribonucleate following fixation by transformable bacteria. Nature 187, 1004-1006.

Gasc, A. M., Kauc, L., Baraillé, P., Sicard, A. M. \& Goodgal, S. (1991). Gene localization, size and physical map of the chromosome of Streptococcus pneumoniae. I Bacteriol 173, 7361-7367.

Ghei, O. K. \& Lacks, S. A. (1967). Recovery of donor deoxyribonucleic acid marker activity from eclipse in pneumococcal transformation. J Bacteriol 93, 816-829.

Griffith, F. (1928). The significance of pneumococcal types. J Hyg 27, 113-159.

Havarstein, L. S., Coomaraswamy, G. \& Morrison, D. A. (1995). An unmodified heptadecapeptide induces competence for genetic transformation in Streptococcus pneumoniae. Proc Natl Acad Sci USA 92, 11140-11144.

Heidelberger, M. \& Avery, O. T. (1922). Soluble specific substance of pneumococcus. J Exp Med 38, 73-79.

Kauc, L., Mitchell, M. \& Goodgal, S. H. (1989). Size and physical map of the chromosome of Haemophilus influenzae. J Bacteriol 171, 2472-2479.

Kent, J. L. \& Hotchkiss, R. D. (1964). Kinetic analysis of multiple, linked recombinations in pneumococcal transformation. $J \mathrm{Mol}$ Biol 9, 308-322.

Lacks, S. (1962). Molecular fate of DNA in genetic transformation of pneumococcus. J Mol Biol 5, 119-131.

Lacks, S. (1970). Mutants of Diplococcus pneumoniae that lack deoxyribonucleases and other activities possibly pertinent to genetic transformation. J Bacteriol 101, 373-383.

Lacks, S., Greenberg, B. \& Neuberger, M. (1974). Role of a deoxyribonuclease in the genetic transformation of Diplococcus pneumoniae. Proc Natl Acad Sci USA 71, 2305-2309.

Laible, G., Hakenbeck, R., Sicard, M. A., Joris, B. \& Ghuysen, J. M. (1989). Nucleotide sequences of the $p b p X$ genes encoding the penicillin-binding proteins $2 \mathrm{x}$ from Streptococcus pneumoniae R6 and a cefotaxime-resistant mutant, C506. Mol Microbiol 3, 1337-1348.

Leach, F. S., Nicolaides, N. C., Papadopoulos, N. \& 32 other authors (1993). Mutations of a mutS homolog in hereditary nonpolyposis colorectal cancer. Cell 75, 1215-1225.
Lefevre, J. C., Claverys, J. P. \& Sicard, A. M. (1979). Donor deoxyribonucleic acid length and marker effect in pneumococcal transformation. J Bacteriol 138, 80-86.

Lefrançois, J. \& Sicard, A. M. (1997). Electrotransformation of Streptococcus pneumoniae: evidence for restriction of the DNA on entry. Microbiology 143, 523-526.

Lopez, P., Espinoza, M., Stassi, D. L. \& Lacks, S. A. (1982). Facilitation of plasmid transfer in Streptococcus pneumoniae by chromosomal homology. J Bacteriol 150, 692-701.

Martin, B., Garcia, P., Castanié, M. P. \& Claverys, J. P. (1995). The recA gene of Streptococcus pneumoniae is part of a competenceinduced operon and controls lysogenic induction. Mol Microbiol $15,367-379$.

Méjean, V. \& Claverys, J. P. (1988). Polarity of DNA entry in transformation of Streptococcus pneumoniae. Mol Gen Genet 213, 444-448.

Méjean, V. \& Claverys, J. P. (1993). DNA processing during entry in transformation of Streptococcus pneumoniae. J Biol Chem 268, 5594-5599.

Mitchell, M. A., Skowronek, K., Kauc, L. \& Goodgal, S. (1991). Electroporation of Haemophilus influenzae is effective for transformation of plasmid but not chromosomal DNA. Nucleic Acids Res 19, 3625-3628.

Morrison, D. A. (1978). Transformation in pneumococcus: Protein content of eclipse complex. J Bacteriol 136, 548-557.

Morrison, D. A. \& Baker, M. (1979). Competence for genetic transformation in pneumococcus depends on synthesis of a small set of proteins. Nature 282, 215-217.

Morrison, D. A., Lacks, S. A., Guild, W. R. \& Hageman, J. M. (1983). Isolation and characterization of three new classes of transformation deficient mutants of Streptococcus pneumoniae that are defective in DNA transport and genetic recombination. $J$ Bacteriol 156, 281-290.

Prats, H., Martin, B., Pognonec, P., Burger, A. C. \& Claverys, J. P. (1985a). A plasmid vector allowing positive selection of recombinant plasmids in Streptococcus pneumoniae. Gene 39 , $41-48$.

Prats, H., Martin, B. \& Claverys, J. P. (1985b). The hexB mismatch repair gene of Streptococcus pneumoniae: characterization, cloning and identification of the product. Mol Gen Genet 200, $482-489$.

Sambrook, J., Fritsch, E. F. \& Maniatis, T. (1989). Molecular Cloning: a Laboratory Manual, 2nd edn. Cold Spring Harbor, NY: Cold Spring Harbor Laboratory.

Saunders, C. W. \& Guild, W. R. (1981). Monomer plasmid DNA transforms Streptococcus pneumoniae. Mol Gen Genet 181, $57-62$.

Sicard, A. M. (1964). A new synthetic medium for Diplococcus pneumoniae and its use for the study of reciprocal transformation at the amiA locus. Genetics 50, 31-44.

Southern, E. M. (1975). Detection of specific sequences among DNA fragments separated by gel electrophoresis. J Mol Biol 98, 503-517.

Received 2 March 1998; revised 26 June 1998; accepted 2 July 1998. 